\title{
Discrimination of cryptochirality in chiral isotactic polystyrene by asymmetric autocatalysis $\dagger$
}

\author{
Tsuneomi Kawasaki, ${ }^{a b}$ Christiane Hohberger, ${ }^{c}$ Yuko Araki, ${ }^{a}$ Kunihiko Hatase, ${ }^{a}$ \\ Klaus Beckerle, ${ }^{c}$ Jun Okuda ${ }^{* c}$ and Kenso Soai ${ }^{* a b}$
}

Received (in College Park, MD, USA) 29th June 2009, Accepted 30th July 2009

First published as an Advance Article on the web 21st August 2009

DOI: $10.1039 / b 912813 a$

\begin{abstract}
Chiral isotactic polystyrenes induce the enantioselective addition of diisopropylzinc to pyrimidine-5-carbaldehyde, affording the enantiomerically enriched pyrimidyl alkanol with the corresponding absolute configuration to that of cryptochiral polystyrenes in conjunction with asymmetric autocatalysis.
\end{abstract}

Chirality plays a significant role in chemical, biological, pharmaceutical and material science. ${ }^{1}$ The study of chirality has been developed as an innovative technique ${ }^{2}$ for distinguishing between a pair of enantiomers. In general, optically active materials are chiral, but not all chiral materials are optically active. The optically inactive but chiral molecules exhibit cryptochirality. ${ }^{3,4}$

The phenomenon of cryptochirality can be observed in isotactic poly( $\alpha$-olefins) such as polypropylenes and polystyrenes. Neglecting the chain ends, poly( $\alpha$-olefins) feature a $C_{\mathrm{s}}$ symmetry and therefore possess a pseudo-mirror plane (Fig. 1). ${ }^{5}$ Because of the recent development of single-site catalysts for the synthesis of stereoregular and enantiomerically pure poly( $\alpha$-olefins $)$, it is now possible to correlate the chiroptical properties isotactic poly( $\alpha$-olefins) with their chain length. ${ }^{6}$

Previously we reported on the synthesis of enantioenriched isotactic polystyrene $\mathbf{1}^{7}$ It was prepared using a chiral

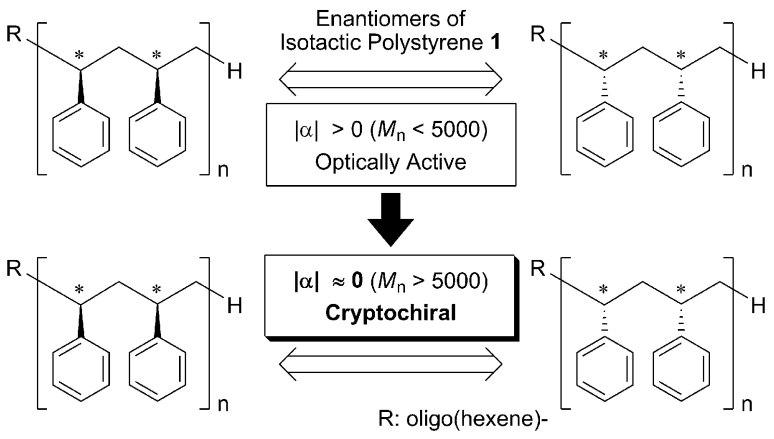

Fig. 1 Cryptochirality in isotactic polystyrene 1.

${ }^{a}$ Department of Applied Chemistry, Tokyo University of Science, Kagurazaka, Shinjuku-ku, Tokyo 162-8601, Japan.

E-mail: soai@rs.kagu.tus.ac.jp; Fax: +81352614631;

Tel: +81352288261

${ }^{b}$ Research Institute of Science and Technology, Tokyo University of Science, Kagurazaka, Shinjuku-ku, Tokyo 162-8601, Japan

${ }^{c}$ Institute of Inorganic Chemistry, RWTH Aachen University,

Landoltweg 1, D-52074 Aachen, Germany.

E-mail:jun.okuda@ac.rwth-aachen.de

$\dagger$ Electronic supplementary information (ESI) available: The asymmetric autocatalysis induced by bis(phenol) $\mathbf{5}$. See DOI: 10.1039/b912813a

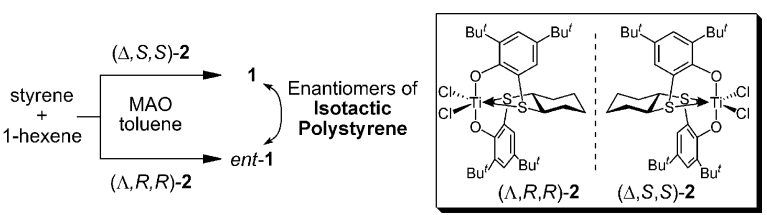

Fig. 2 Synthesis of polystyrene 1 and the structure of the (OSSO)type chiral ligand $\mathbf{2}$.

titanium catalyst based on the (OSSO)-type ligand $\mathbf{2}^{7 a, 8}$ and 1-hexene as a chain transfer agent (Fig. 2). The dependence of the specific rotation value on the molecular weight of the isotactic polystyrenes has been demonstrated. ${ }^{7}$ Although low-molecular-weight polystyrene can be optically active, no optical activity was detected for high-molecular-weight polymers $\left(M_{\mathrm{n}}>5000\right)$; i.e., high-molecular-weight polystyrene 1 possesses cryptochirality (Fig. 1).

How can one discriminate between the enantiomers of cryptochiral compounds? To the best of our knowledge, there is no contemporary method available to determine the cryptochirality of high-molecular-weight isotactic polystyrene. It should be noted that polystyrene does not have heteroatoms. Thus, the development of a method for the recognition of the enantiomeric forms of isotactic polystyrene is a challenge.

We developed a highly sensitive method to detect molecular chirality by using asymmetric autocatalysis ${ }^{9-12}$ with amplification of enantiomeric excess (ee). ${ }^{13}$ In the presence of a chiral compound, the enantioselective addition of diisopropylzinc $\left(i \mathrm{Pr}_{2} \mathrm{Zn}\right)$ to a pyrimidine-5-carbaldehyde $\mathbf{3}$ affords highly enantioenriched $(S)$ - or $(R)$-pyrimidyl alkanol $\mathbf{4}$, whose absolute configuration is efficiently controlled by the absolute configuration of an added chiral compound. ${ }^{14}$ Many types of chiral compounds have been used as chiral inducers in asymmetric autocatalysis, including cryptochiral small hydrocarbon molecules, ${ }^{15}$ but to date, there has been no report on the use of cryptochiral polymers that consist exclusively of hydrocarbons.

Here, we report on the highly enantioselective addition of $i \operatorname{Pr}_{2} \mathrm{Zn}$ to pyrimidine-5-carbaldehyde 3 in the presence of enantioenriched isotactic polystyrene $\mathbf{1}$ and ent-1 $\left(M_{\mathrm{n}}\right.$ 6000-6100 $\left.\mathrm{g} \mathrm{mol}^{-1}\right)$ with no detectable optical rotation (Scheme 1). It was found that the cryptochirality of isotactic polystyrene was successfully recognized in conjunction with asymmetric autocatalysis.

Table 1 shows the results of the asymmetric autocatalysis triggered by enantiomers of the cryptochiral isotactic polystyrene $\mathbf{1}$. The stereochemical correlations of the cryptochirality 


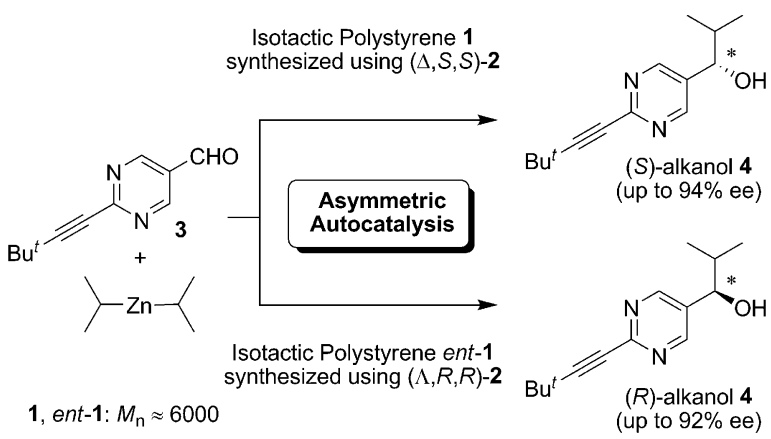

Scheme 1 Enantioselective addition of $i \operatorname{Pr}_{2} \mathrm{Zn}$ to aldehyde 3 induced by homochiral polystyrene $\mathbf{1}$, followed by asymmetric autocatalytic amplification of enantiomeric purity.

and the absolute configurations of the resulting 5-pyrimidyl alkanol 4 are depicted. When $i \operatorname{Pr}_{2} \mathrm{Zn}$ addition to pyrimidine-5carbaldehyde 3 was performed in the presence of polystyrene 1, synthesized using $(\Delta, S, S)$-2 as a polymerization catalyst, pyrimidyl alkanol $\mathbf{4}$ with $S$-configuration was obtained with $15 \%$ ee and $85 \%$ isolated yield (Table 1, entry 1 ). On the other hand, the enantiomer of isotactic polystyrene 1 (ent-1), prepared using $(\Lambda, R, R)$-2 as chiral ligand, afforded $(R)$-alkanol 4 with $5 \%$ ee in $89 \%$ isolated yield. The reproducibility of the stereochemical outcome is clearly shown in entries 3-8.

The chiral catalyst $\mathbf{2}$ used in the polymerization reaction can be separated from the polystyrene 1 by purification using silica gel and a reprecipitation technique. ${ }^{7 a}$ Analytical thin layer chromatography was used to check for the absence of bis(phenol) 5, which is a chiral organic moiety of titanium complex 2, from polystyrene $\mathbf{1}$. However, considering the possibility of incomplete separation of chiral bis(phenol) $\mathbf{5}$ from cryptochiral polystyrene $\mathbf{1}$, and the asymmetric induction by the remaining bis(phenol) $\mathbf{5},{ }^{16}$ isotactic polystyrene $\mathbf{1}$ used in entries 9 and 10 were prepared by mixing the opposite enantiomer of $\mathbf{5}$ to that utilized in the polymerization reaction, followed by repurification using silica gel column chromatography. The results of entries 9 and 10 strongly support the stereochemical correlations between cryptochiral 1/ent-1 and $(S) /(R)$-pyrimidyl alkanol 4. Although the enantiomeric excesses of the resulting pyrimidyl alkanol 4 reported in Table 1 are only in the range of $1.1-15 \%$ ee, it is possible to increase the ee value of the final product 4 by applying consecutive asymmetric autocatalysis.

In Table 2, entry 1 , consecutive asymmetric autocatalysis ${ }^{13}$ was performed for the purpose of enhancing enantiomer purity to afford (S)-4 with $87 \%$ ee. Further asymmetric autocatalysis with amplification of ee has also been applied in entries 2-8 to afford highly enantioenriched $(R)$ and $(S)$-alkanols 4 with $67-86 \%$ ee. It should be noted that the enantioselectivity in entries 1-8 was the same as observed in Table 1; i.e., isotactic polystyrene 1 obtained from the polymerization catalyzed by $(\Delta, S, S)-\mathbf{2}$ initiated the formation of $(S)$-alkanol 4, and ent-1 synthesized via catalysis of $(\Lambda, R, R)$-2 triggered the generation of alkanol $\mathbf{4}$ with $R$-configuration. Furthermore, an additional three rounds of asymmetric autocatalysis afforded the $(S)$ - and $(R)$-product 4 with 94 and $92 \%$ ee, as shown in entries 9 and 10 .
Table 1 Chiral recognition of cryptochirality in isotactic polystyrene $\mathbf{1}$ and ent $\mathbf{1}$ by asymmetric autocatalysis

\begin{tabular}{|c|c|c|c|c|c|}
\hline \multirow[b]{2}{*}{ Entry $^{a}$} & \multirow{2}{*}{$\begin{array}{l}\text { Optically inactive } \\
\text { isotactic } \\
\text { polystyrene } \mathbf{1}^{b}\end{array}$} & \multirow{2}{*}{$\begin{array}{l}\text { Catalyst } \\
\text { used for } \\
\text { synthesis }\end{array}$} & \multicolumn{3}{|c|}{ 5-Pyrimidyl alkanol 4} \\
\hline & & & $\begin{array}{l}\text { Isolated } \\
\text { yield }(\%)\end{array}$ & $\begin{array}{l}\mathrm{Ee} \\
(\%)^{c}\end{array}$ & Config \\
\hline 1 & 1 & $(\Delta, S, S)-2$ & 85 & 15 & $S$ \\
\hline 2 & ent -1 & $(\Lambda, R, R)-2$ & 89 & 5 & $R$ \\
\hline 3 & 1 & $(\Delta, S, S)-2$ & 82 & 6 & $S$ \\
\hline 4 & ent-1 & $(\Lambda, R, R)-\mathbf{2}$ & 88 & 4 & $R$ \\
\hline 5 & 1 & $(\Delta, S, S)-\mathbf{2}$ & 83 & 1.4 & $S$ \\
\hline 6 & ent $\mathbf{1}$ & $(\Lambda, R, R)-\mathbf{2}$ & 83 & 1.1 & $R$ \\
\hline 7 & 1 & $(\Delta, S, S)-2$ & 89 & 3 & $S$ \\
\hline 8 & ent $\mathbf{1}$ & $(\Lambda, R, R)-\mathbf{2}$ & 84 & 3 & $R$ \\
\hline $9^{d}$ & 1 & $(\Delta, S, S)-2$ & 91 & 1.3 & $S$ \\
\hline $10^{e}$ & ent $\mathbf{1}$ & $(\Lambda, R, R)-2$ & 88 & 3 & $R$ \\
\hline
\end{tabular}

${ }^{a}$ The molar ratio of polystyrene 1 : pyrimidine-5-carbaldehyde $3: i \operatorname{Pr}_{2} \mathrm{Zn}=0.018: 0.525: 1.18(\mathrm{mmol})$. The general procedure for asymmetric autocatalysis (Table 1 , entry 1) is as follows: $i \operatorname{Pr}_{2} \mathrm{Zn}$ $(0.08 \mathrm{mmol}, 0.8 \mathrm{~mL} ; 1.0 \mathrm{M}$ toluene solution) was added dropwise to a toluene $(0.75 \mathrm{~mL})$ solution of polystyrene $1(10 \mathrm{mg}, c a .0 .018 \mathrm{mmol})$. To this solution was added a toluene $(0.25 \mathrm{~mL})$ solution of aldehyde 3 ( $4.7 \mathrm{mg}, 0.025 \mathrm{mmol}$ ) over a period of $1.5 \mathrm{~h}$ at $0{ }^{\circ} \mathrm{C}$. After stirring the mixture for $15 \mathrm{~h}$, toluene $(1 \mathrm{~mL})$ and $i \operatorname{Pr}_{2} \mathrm{Zn}(0.3 \mathrm{mmol}, 0.3 \mathrm{~mL} ; 1.0 \mathrm{M}$ toluene solution) were then added at $0{ }^{\circ} \mathrm{C}$, and the mixture was stirred for $1 \mathrm{~h}$. A toluene $(0.75 \mathrm{~mL})$ solution of $3(18.8 \mathrm{mg}, 0.1 \mathrm{mmol})$ was slowly added, and the reaction mixture was stirred at $0{ }^{\circ} \mathrm{C}$ for $1.5 \mathrm{~h}$. Then, toluene $(5.0 \mathrm{~mL}), i \operatorname{Pr}_{2} \mathrm{Zn}(0.8 \mathrm{mmol}, 0.8 \mathrm{~mL} ; 1.0 \mathrm{M}$ toluene solution) and a toluene $(2.0 \mathrm{~mL})$ solution of $3(75.3 \mathrm{mg}, 0.4 \mathrm{mmol})$ were added successively at $0{ }^{\circ} \mathrm{C}$. After stirring the mixture for $2.5 \mathrm{~h}$, the reaction was quenched with $\mathrm{HCl}(1 \mathrm{M}, 3 \mathrm{~mL})$ and neutralized with a saturated $\mathrm{NaHCO}_{3}$ solution $(9 \mathrm{~mL})$. The mixture was then filtered through Celite and the filtrate was extracted with AcOEt (three times). The combined organic layers were dried over anhydrous $\mathrm{Na}_{2} \mathrm{SO}_{4}$ and concentrated in vacuo. Purification of the residue by silica gel column chromatography on silica gel (hexane-AcOEt, $3: 1$, v/v) afforded the $(S)$-pyrimidyl alkanol $4(103.1 \mathrm{mg}, 0.444 \mathrm{mmol})$ in $85 \%$ yield. The ee value was determined to be $15 \%$ by HPLC, using a chiral stationary phase (Daicel Chiralpak IB $4.6 \Phi \times 250 \mathrm{~mm}, 254 \mathrm{~nm}$ UV detector, room temperature, eluent: $5 \%$ 2-propanol in hexane $(\mathrm{v} / \mathrm{v}), 1.0 \mathrm{~mL} \mathrm{~min}^{-1}$, retention time: $11 \mathrm{~min}$ for $(S)-4$ and $16 \mathrm{~min}$ for $(R)-\mathbf{4}) .{ }^{b}$ For the synthesis and properties of 1 , see ref. 7. $M_{\mathrm{n}}$ values are $6108 \mathrm{~g} \mathrm{~mol}^{-1}$ for 1 and $6006 \mathrm{~g} \mathrm{~mol}^{-1}$ for ent $-1 .{ }^{c}$ The ee value was determined by HPLC using a chiral stationary phase. ${ }^{d}(R, R)$-Bis(phenol) $\mathbf{5}$, which is a chiral organic part of catalyst $(\Lambda, R, R)-\mathbf{2}$ was mixed with the polystyrene $\mathbf{1}$, and $(R, R)-\mathbf{5}$ and polystyrene $\mathbf{1}$ were separated again using silica gel column chromatography before use as a chiral initiator of asymmetric autocatalysis. See also ref. $16{ }^{e}(S, S)$-Bis(phenol) 5 was mixed with the polystyrene ent-1, and $(S, S)-\mathbf{5}$ and ent-1 are separated again using silica gel column chromatography before use as a chiral initiator of asymmetric autocatalysis. See also ref. 16.

In this enantioselective reaction, cryptochirality caused by a small relative difference between the end groups of the enantiomeric polystyrene chains may control the $s i$ - or $r e$-enantioface selection of $i \operatorname{Pr}_{2} \mathrm{Zn}$ addition to pyrimidine-5-carbaldehyde 3 to afford the isopropylzinc alkoxide of pyrimidyl alkanol 4 (autocatalyst) with a minute enantiomeric imbalance. Once the asymmetric autocatalyst with a small enantiomeric enrichment is generated, the enantiomeric purity of pyrimidyl alkanol 4 increases during the addition of $i \operatorname{Pr}_{2} \mathrm{Zn}$ to aldehyde $\mathbf{3}$ thanks to the asymmetric autocatalysis. ${ }^{17}$ Thus, chiral alkanol $\mathbf{4}$ with an absolute configuration corresponding to that of chiral polymer $\mathbf{1}$ is formed in a highly enantioenriched form. We can therefore 
Table 2 Chiral recognition of cryptochirality of isotactic polystyrene 1 followed by consecutive asymmetric autocatalysis with amplification of enantiomeric excess

5-Pyrimidyl alkanol 4

\begin{tabular}{|c|c|c|c|c|c|}
\hline Entry $^{a}$ & $\begin{array}{l}\text { Optically inactive } \\
\text { isotactic polystyrene } \mathbf{1}^{b}\end{array}$ & $\begin{array}{l}\text { Catalyst used } \\
\text { for synthesis }\end{array}$ & $\begin{array}{l}\text { Isolated } \\
\text { yield }(\%)\end{array}$ & $\begin{array}{l}\mathrm{Ee} \\
(\%)^{c}\end{array}$ & Config. \\
\hline 1 & 1 & $(\Delta, S, S)-2$ & 93 & 87 & $S$ \\
\hline 2 & ent $\mathbf{1}$ & $(\Lambda, R, R)-\mathbf{2}$ & 85 & 77 & $R$ \\
\hline 3 & 1 & $(\Delta, S, S)-2$ & 88 & 67 & $S$ \\
\hline 4 & ent $\mathbf{1}$ & $(\Lambda, R, R)-\mathbf{2}$ & 87 & 84 & $R$ \\
\hline 5 & 1 & $(\Delta, S, S)-\mathbf{2}$ & 93 & 78 & $S$ \\
\hline 6 & ent-1 & $(\Lambda, R, R)-\mathbf{2}$ & 93 & 63 & $R$ \\
\hline 7 & 1 & $(\Delta, S, S)-2$ & 94 & 86 & $S$ \\
\hline 8 & ent -1 & $(\Lambda, R, R)-2$ & 91 & 69 & $R$ \\
\hline $9^{d}$ & 1 & $(\Delta, S, S)-2$ & 99 & 94 & $S$ \\
\hline $10^{d}$ & ent -1 & $(\Lambda, R, R)-2$ & 99 & 92 & $R$ \\
\hline
\end{tabular}

${ }^{a}$ On completion of the general experimental procedure, an additional two cycles of asymmetric autocatalysis with amplification of ee were performed. See ref. 13. ${ }^{b}$ See Table 1 , footnote b. ${ }^{c}$ See Table 1, footnote c. ${ }^{d}$ On completion of the general experimental procedure, an additional three cycles of asymmetric autocatalytic amplification were performed. See ref. 13.

distinguish the enantiomeric form of cryptochiral polystyrene $\mathbf{1}$ by determining the absolute configuration of the resulting alkanol 4. The detailed mechanism of the amplification of enantiomeric excess in asymmetric autocatalysis is now under investigation. The results will be reported in due course.

On the other hand, when polystyrenes with higher molecular weights $\left(M_{\mathrm{n}}>c a .600000 \mathrm{~g} \mathrm{~mol}^{-1}\right)$ were used in the asymmetric autocatalysis, no reproducible results were obtained (thus far). This may be ascribed to further minute cryptochirality of $\mathbf{1}$, the occurrence of stereoerrors and/or low solubility in toluene.

In summary, we have demonstrated that asymmetric autocatalysis is a useful method for sensing cryptochirality of homochiral isotactic polystyrene 1. Homochiral polystyrenes autocatalytically induce the enantioselective addition of $i \operatorname{Pr}_{2} \mathrm{Zn}$ to pyrimidine-5-carbaldehyde 3 to afford the pyrimidyl alkanol 4 with the corresponding absolute configurations to that of cryptochiral polystyrenes. Cryptochirality of isotactic polystyrene, which cannot be distinguished between the enantiomeric forms by applying any contemporary technique, can be discriminated as the visible chirality of autocatalyst 4 by asymmetric autocatalysis with amplification of chirality.

\section{Notes and references}

1 E. L. Eliel and S. W. Wilen, Stereochemistry of Organic Compounds, Wiley, New York, 1994.

2 (a) K. Nakanishi, N. Berova and R. W. Woody, Circular Dichroism: Principles and Applications, Wiley, New York, 2000; (b) J. Haesler, I. Schindelholz, E. Riguet, C. G. Bochet and W. Hug, Nature, 2007, 446, 526; (c) L. A. Nafie and T. B. Freedman, Enantiomer, 1998, 3, 283; (d) L. D. Barron, Nature, 1972, 238, 17; (e) Y. Okamoto, E. Yashima and C. Yamamoto, Top. Stereochem., 2003, 24, 157; (f) U. J. Meierhenrich, W. H.-P. Thiemann, F. Goesmann, R. Roll and H. Rosenbauer, Chirality, 2001, 13, 454.

3 (a) K. Mislow and P. Bickart, Isr. J. Chem., 1976-1977, 15, 1; (b) K. Mislow, Collect. Czech. Chem. Commun., 2003, 68, 849.

4 (a) M. M. Green and S. K. Jha, Chirality, 1997, 9, 424; (b) C. W. Thomas and Y. Tor, Chirality, 1998, 10, 53.

5 (a) M. Farina, Top. Stereochem., 1987, 17, 1; (b) P. Pino, P. Cioni and J. Wei, J. Am. Chem. Soc., 1987, 109, 6189; (c) K. Nozaki, J. Polym. Sci., Part A: Polym. Chem., 2004, 42, 215.
6 J.-F. Carpentier, Angew. Chem., Int. Ed., 2007, 46, 6404.

7 (a) K. Beckerle, R. Manivannan, B. Lian, G.-J. M. Meppelder, G. Raabe, T. P. Spaniol, H. Ebeling, F. Pelascini, R. Mülhaupt and J. Okuda, Angew. Chem., Int. Ed., 2007, 46, 4790; (b) G.-J. M. Meppelder, K. Beckerle, R. Manivannan, B. Lian, G. Raabe, T. P. Spaniol and J. Okuda, Chem.-Asian J., 2008, 3, 1312.

8 Experimental procedure for a related racemic ligand, see: K. Marcseková, C. Loos, F. Rominger and S. Doye, Synlett, 2007, 16, 2564.

9 K. Soai, T. Shibata, H. Morioka and K. Choji, Nature, 1995, 378, 767.

10 Reviews by other groups: (a) J. Podlech and T. Gehring, Angew. Chem., Int. Ed., 2005, 44, 5776; (b) C. Bolm, F. Bienewald and A. Seger, Angew. Chem., Int. Ed. Engl., 1996, 35, 1657; (c) M. H. Todd, Chem. Soc. Rev., 2002, 31, 211; (d) M. Avalos, R. Babiano, P. Cintas, J. L. Jiménez and J. C. Palacios, Chem. Commun., 2000, 887; (e) H. Buschmann, R. Thede and D. Heller, Angew. Chem., Int. Ed., 2000, 39, 4033; $(f)$ K. Mikami and M. Yamanaka, Chem. Rev., 2003, 103, 3369; (g) I. D. Gridnev, Chem. Lett., 2006, 35, 148; (h) L. Caglioti, C. Zucchi and G. Pályi, Chemistry Today (Chimica Oggi), 2005, 23, 38.

11 Reviews by our group: (a) K. Soai, T. Shibata and I. Sato, Acc. Chem. Res., 2000, 33, 382; (b) K. Soai, T. Shibata and I. Sato, Bull. Chem. Soc. Jpn., 2004, 77, 1063; (c) K. Soai and T. Kawasaki, Chirality, 2006, 18, 469; (d) K. Soai and T. Kawasaki, Top. Curr. Chem., 2008, 284, 1; (e) K. Soai and T. Kawasaki, in Organometallic Chirality, ed. G. Palyi, C. Zucchi and L. Caglioti, Mucchi Editore, Modena, 2008, ch. 6, p. 107.

12 (a) T. Shibata, H. Morioka, T. Hayase, K. Choji and K. Soai, J. Am. Chem. Soc., 1996, 118, 471; (b) T. Shibata, S. Yonekubo and K. Soai, Angew. Chem., Int. Ed., 1999, 38, 659; (c) I. Sato, T. Yanagi and K. Soai, Chirality, 2002, 14, 166; (d) F. Lutz, T. Kawasaki and K. Soai, Tetrahedron: Asymmetry, 2006, 17, 486.

13 I. Sato, H. Urabe, S. Ishiguro, T. Shibata and K. Soai, Angew. Chem., Int. Ed., 2003, 42, 315.

14 (a) T. Shibata, J. Yamamoto, N. Matsumoto, S. Yonekubo, S. Osanai and K. Soai, J. Am. Chem. Soc., 1998, 120, 12157; (b) K. Soai, S. Osanai, K. Kadowaki, S. Yonekubo, T. Shibata and I. Sato, J. Am. Chem. Soc., 1999, 121, 11235; (c) I. Sato, D. Omiya, T. Saito and K. Soai, J. Am. Chem. Soc., 2000, 122, 11739; (d) T. Kawasaki, M. Sato, S. Ishiguro, T. Saito, Y. Morishita, I. Sato, H. Nishino, Y. Inoue and K. Soai, J. Am. Chem. Soc., 2005, 127, 3274; (e) T. Kawasaki, K. Suzuki, Y. Hakoda and K. Soai, Angew. Chem., Int. Ed., 2008, 47, 496; (f) T. Kawasaki, Y. Matsumura, T. Tsutsumi, K. Suzuki, M. Ito and K. Soai, Science, 2009, 324, 492.

15 T. Kawasaki, H. Tanaka, T. Tsutsumi, T. Kasahara, I. Sato and K. Soai, J. Am. Chem. Soc., 2006, 128, 6032.

16 The direction of asymmetric induction has been examined employing $(S, S)$ and $(R, R)$-bis(phenol) 5 as a chiral initiator of asymmetric autocatalysis, respectively. As a result of asymmetric autocatalysis, $(S, S)$-bis(phenol) 5 induced the formation of $(S)$-pyrimidyl alkanol 4 with a high ee value, and $(R, R)-5$ promoted the production of enantiomerically enriched $(R)$-alkanol $\mathbf{4}$, respectively. The results are detailed in the ESI $\dagger$.
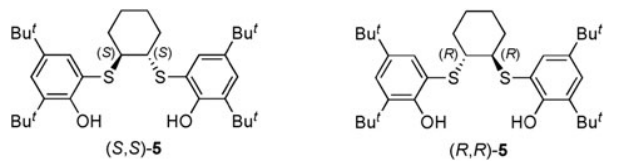

17 (a) I. Sato, D. Omiya, H. Igarashi, K. Kato, Y. Ogi, K. Tsukiyama and K. Soai, Tetrahedron: Asymmetry, 2003, 14, 975; (b) I. D. Gridnev, J. M. Serafimov and J. M. Brown, Angew. Chem., Int. Ed., 2004, 43, 4884; (c) D. G. Blackmond, Proc. Natl. Acad. Sci. U. S. A., 2004, 101, 5732; (d) J. R. Islas, D. Lavabre, J.-M. Grevy, R. H. Lamoneda, H. R. Cabrera, J.-C. Micheau and T. Buhse, Proc. Natl. Acad. Sci. U. S. A., 2005, 102, 13743; (e) Y. Saito and H. Hyuga, Top. Curr. Chem., 2008, 284, 97; (f) G. Lente, J. Phys. Chem. A, 2005, 109, 11058; $(g)$ K. Micskei, G. Pota, L. Caglioti and G. Palyi, J. Phys. Chem. A, 2006, 110, 5982; (h) J. M. Brown, I. Gridnev and J. Klankermayer, Top. Curr. Chem., 2008, 284, 35; (i) D. Lavabre, J.-C. Micheau, J. R. Islas and T. Buhse, Top. Curr. Chem., 2008, 284, 67; (j) F. Lutz, T. Igarashi, T. Kinoshita, M. Asahina, K. Tsukiyama, T. Kawasaki and K. Soai, J. Am. Chem. Soc., 2008, 130, 2956. 